\title{
Methylphenidate improves deficient error evaluation in children with ADHD: an event-related brain potential study
}

Citation for published version (APA):

Jonkman, L. M., van Melis, J. J. M., Kemner, C., \& Markus, C. R. (2007). Methylphenidate improves deficient error evaluation in children with ADHD: an event-related brain potential study. Biological Psychology, 76(3), 217-229. https://doi.org/10.1016/j.biopsycho.2007.08.004

Document status and date:

Published: 01/01/2007

DOI:

10.1016/j.biopsycho.2007.08.004

Document Version:

Publisher's PDF, also known as Version of record

\section{Document license:}

Taverne

Please check the document version of this publication:

- A submitted manuscript is the version of the article upon submission and before peer-review. There can be important differences between the submitted version and the official published version of record.

People interested in the research are advised to contact the author for the final version of the publication, or visit the DOI to the publisher's website.

- The final author version and the galley proof are versions of the publication after peer review.

- The final published version features the final layout of the paper including the volume, issue and page numbers.

Link to publication

\footnotetext{
General rights rights.

- You may freely distribute the URL identifying the publication in the public portal. please follow below link for the End User Agreement:

www.umlib.nl/taverne-license

Take down policy

If you believe that this document breaches copyright please contact us at:

repository@maastrichtuniversity.nl

providing details and we will investigate your claim.
}

Copyright and moral rights for the publications made accessible in the public portal are retained by the authors and/or other copyright owners and it is a condition of accessing publications that users recognise and abide by the legal requirements associated with these

- Users may download and print one copy of any publication from the public portal for the purpose of private study or research.

- You may not further distribute the material or use it for any profit-making activity or commercial gain

If the publication is distributed under the terms of Article $25 \mathrm{fa}$ of the Dutch Copyright Act, indicated by the "Taverne" license above, 


\title{
Methylphenidate improves deficient error evaluation in children with ADHD: An event-related brain potential study
}

\author{
Lisa.M. Jonkman $^{\text {a,* }}$, Jessica. J.M. van Melis ${ }^{\text {a }}$, Chantal Kemner ${ }^{\text {a,b }}$, C. Rob Markus ${ }^{c}$ \\ ${ }^{a}$ Maastricht University, Faculty of Psychology, Department of Cognitive Neuroscience, The Netherlands \\ ${ }^{\mathrm{b}}$ Department of Child and Adolescent Psychiatry, University Medical Center, Utrecht, The Netherlands \\ ${ }^{\mathrm{c}}$ Maastricht University, Faculty of Psychology, Department of Neuropsychology and Psychopharmacology, The Netherlands \\ Received 19 March 2007; accepted 20 August 2007 \\ Available online 24 August 2007
}

\begin{abstract}
Children with ADHD make more errors than control children in response-conflict tasks. To explore whether this is mediated by enhanced sensitivity to conflict or reduced error-processing, task-related brain activity (N2, Ne/ERN, Pe) was compared between 8- to 12-year-old children with ADHD and healthy controls during performance of a flanker task. Furthermore, effects of methylphenidate were investigated in ADHD children in a second study.

ADHD children made more errors, especially in high-response-conflict conditions, without showing post-error slowing. N2 amplitudes were enhanced on trials resulting in an error response, Ne/ERN amplitude was unaffected and Pe amplitude was reduced in the ADHD group. Methylphenidate reduced errors in both low- and high-conflict conditions and normalized Pe amplitudes in children with ADHD. It was concluded that the inaccurate behaviour of ADHD children in conflict tasks might be related to reduced error-awareness and higher sensitivity to response conflict. Methylphenidate's ameliorating effects might be established through its influence on brain networks including posterior (parietal) cortex, enabling children with ADHD to allocate more attention to significant events.
\end{abstract}

(C) 2007 Elsevier B.V. All rights reserved.

Keywords: ADHD; ERP; Response conflict; Methylphenidate; Error processing; ERN; Pe; Dopamine

\section{Introduction}

Attention-deficit hyperactivity disorder (ADHD) is a highly prevalent psychiatric disorder associated with severe cognitivebehavioural dysfunction including hyperactivity, impulsivity and/or inattention. During the last decades, research has clearly shown that ADHD patients perform worse than their normaldeveloping peers on a broad range of different tasks and particularly exhibit slow, variable and less accurate response patterns (Seidel and Joschoko, 1990; Johnson et al., 2007). Furthermore, it has been demonstrated that ADHD children not only make more errors in general but also show worse task performance particularly during interference from irrelevant stimulus information that induces semantic or response conflict

\footnotetext{
* Corresponding author at: Maastricht University, Faculty of Psychology, Department of Neurocognition, P.O. Box 616, 6200 MD Maastricht, The Netherlands.

E-mail address: L.Jonkman@psychology.unimaas.nl (L.M. Jonkman).
}

(Jonkman et al., 1999; Crone et al., 2003; Scheres et al., 2004; Lansbergen et al., 2007). One example of such an interference task is the Eriksen flanker task (Eriksen and Eriksen, 1974) in which two pre-designated target stimuli that require either a left- or a right-hand button press (e.g., letters $\mathrm{E}$ and $\mathrm{H}$ ), are flanked by distracting stimuli that are either congruent (EEEEE or HHHHH) or incongruent (EEHEE or HHEHH) with the target. Several studies report more errors in ADHD children than control children in the flanker task, especially in response to incongruent stimuli (Jonkman et al., 1999; Crone et al., 2003; Scheres et al., 2004). It is however not clear what is causing this reduced accuracy in ADHD children. One possibility is that ADHD children experience more response conflict by incongruent flankers and, thus, may process relevant stimuli less efficient. ADHD children may also be less able to learn from their mistakes due to inaccurate early error-monitoring, or simply because they are less concerned about their own mistakes. Conforming to the latter explanation, typically developing children and adults naturally respond slower on trials following an error (Davies et al., 2004; Gehring and 
Fencsik, 2001; Hajcak et al., 2003; Nieuwenhuis et al., 2002; Schachar et al., 2004; Segalowitz and Davies, 2004). Such posterror slowing has been suggested to indicate a change in strategy to prevent further mistakes (Rabbitt, 1966; Falkenstein et al., 2000) and three studies suggest that such adaptive processes might be compromised in children with ADHD by showing absent or reduced post-error slowing (Sergeant and van der Meere, 1988; Schachar et al., 2004; Wiersema et al., 2005). Due to its high temporal resolution, the event-related brain potential (ERP) method provides the opportunity to investigate potential differences between ADHD and healthy children in how the brain processes information before an error is committed. Whereas, behavioural measures, such as posterror slowing, reflect the final product of information processing, ERPs enable us to study cerebral processes involved in information processing before, during and after the actual response with high temporal resolution.

Different ERP components have been associated with performance-monitoring. In conflict-inducing tasks (like the flanker task), on correct response trials, a negative amplitude has been reported to occur around $200 \mathrm{~ms}$ after stimulus onset above the fronto-central cortex (N2). The N2 amplitude has been reported to be enlarged in conditions where target stimuli are flanked by response incongruent or otherwise distracting stimuli (Van Veen and Carter, 2002a; Nieuwenhuis et al., 2003; Yeung et al., 2004; Bartholow et al., 2005). Two other ERPcomponents that are locked to the incorrect response and hence are associated with error processing, are the error-related Negativity (Ne/ERN) and Positivity (Pe). The Ne/ERN is a negative wave reaching its peak around 60-100 ms after an incorrect response in adults at fronto-central electrodes. The $\mathrm{Ne} / \mathrm{ERN}$ is followed by the Pe, in adults starting around $250 \mathrm{~ms}$ after the incorrect response and having its maximum above central-parietal electrodes. Although the functional significance of the $\mathrm{Ne} / \mathrm{ERN}$ is still under debate, it is generally thought to reflect error signalling whenever there is a mismatch between intended and produced responses (e.g., Falkenstein et al., 1991, 2000; Gehring et al., 1993; Scheffer and Coles, 2000). Since Ne/ERN-like negativity may also occur during correct responses, some have argued that this component reflects the degree of response conflict (Carter et al., 1998; Botvinick et al., 2001). In this latter view, the Ne/ERN signals the need to control for conflicts irrespective of whether the actual response was correct or incorrect. Davies et al. (2001) did however not find any correlations between the stimulus-locked $\mathrm{N} 2$ on correct trials and the ERN component following errors and thus concluded that both components at least represent distinct neurophysiological processes.

Also the Pe has been associated with different functional processes, ranging from conscious error-recognition processes (Nieuwenhuis et al., 2001; Hajcak et al., 2003; O'Connell et al., 2007), response strategy adaptation and compensatory efforts (Leuthold and Sommer, 1999) to emotional concerns about committing an error (Falkenstein et al., 2000; Van Veen and Carter, 2002b). A recent literature review favours the view of the Pe reflecting conscious recognition of errors; as yet little support is found for an association with post-error adaptation or affective error processing (Overbeek et al., 2005). Such a view was supported by recent results reported by O'Connell et al. (2007) that whereas, the ERN was independent of error consciousness, a Pe was only present when subjects were aware of committing an error.

As discussed earlier, two behavioural studies have shown reduced post-error slowing in ADHD children in a Sternberg memory search task (Sergeant and van der Meere, 1988) and a Stop-Signal Task (Schachar et al., 2004), suggesting inadequate behavioural adjustment to errors as compared to controls. Three recent studies have included ERP measures to explore differences in performance monitoring between children with ADHD and control children on a more specific temporal scale. In one study, compared to controls, children with ADHD showed reduced post-error slowing with comparable Ne/ERN but reduced Pe amplitudes (Wiersema et al., 2005). These results were interpreted in terms of ADHD children displaying intact early error-detection (reflected by normal Ne/ERN effects) but being less aware of their erroneous behaviour (reflected by reduced post-error slowing and Pe amplitudes). In contrast, two other studies (Liotti et al., 2005; Van Meel et al., 2007) reported reduced Ne/ERN amplitudes in children with ADHD during performance of a stop signal task and a flanker task, respectively. Burgio-Murphy et al. (2007) reported no performance differences between controls and children with ADHD in an oddball task; the latter group did however show enhanced ERN amplitude but comparable Pe. These inconsistencies between studies might be due to the different nature of errors in the three studies: in Liotti et al. (2005) an error was defined as an unsuccessful attempt to inhibit a pre-potent response in reaction to a stop signal (that might have distracted subjects from the error event or might have made them more aware of it) and in Burgio-Murphy et al. (2007) error trials included false alarms to non-target stimuli and misses. This can, however not be the only explaining factor for ERN differences since in studies by Wiersema et al. (2005) and Van Meel et al. (2007) different ERN patterns were found, while errors were in both studies defined as pressing the wrong response button.

In summary, little is known about the brain activity underlying post-error slowing deficits seen in ADHD children. Furthermore, the difference in paradigms used in the few studies that are available complicates interpretation of the results. There is a lack of studies investigating error-related behaviour and brain processes in children with ADHD using conflict-paradigms like Stroop or flanker tasks that are used in most adult studies reporting on both the Ne/ERN and Pe. From an earlier study (Jonkman et al., 1999) we know that children with ADHD make more (incongruent) errors in flanker tasks compared to controls. To explore the cause of this reduced accuracy, the data of the study of Jonkman et al. (1999) were reanalyzed in the present study to compare behavioural and brain (ERP) measures of error-processing in ADHD and healthy control children to investigate whether the enhanced inaccuracy in the response-incongruent condition is caused by enhanced response conflict (N2), or deficits in early error-detection $(\mathrm{Ne} / \mathrm{ERN})$ and/or late error processing $(\mathrm{Pe})$. 
Another aim of the present study was to investigate how potential deficits in performance monitoring in children with ADHD are influenced by the psychostimulant methylphenidate (MPH). MPH is the most prescribed and most effective drug in ADHD (Volkow and Swanson, 2003; Brown et al., 2005) and exerts its effects by blocking reuptake of dopamine (DA) and norepinephrine (NE) (Pliszka, 2005; Arnsten and Li, 2005). According to a recent theory by Holroyd and Coles (2002), the $\mathrm{Ne} / \mathrm{ERN}$ is thought to be generated when a negative dopaminergic reinforcement-learning signal is conveyed to the ACC via the mesencephalic dopamine system. Studies including healthy adult subjects seem to support such a link between dopamine and the Ne/ERN by either reporting enhanced Ne/ERN amplitudes after intake of the DA-stimulant D-amphetamine (de Bruijn et al., 2004) or reduced Ne/ERN amplitude after intake of the DA-antagonist haloperidol (Zirnheld et al., 2004; de Bruijn et al., 2006). However, a study by Riba et al. (2005) showed that in healthy adults, the $\mathrm{Ne} / \mathrm{ERN}$ was also enlarged after administration of the $\alpha 2$ adrenoceptor antagonist Yohimbine, suggesting an additional role of the noradrenergic system in action monitoring. Whereas, MPH has been reported to have positive effects on post-error slowing in children with ADHD (Krusch et al., 1996) there are, to our knowledge, no studies reporting on the effects of MPH on error-related ERPs of children with ADHD. To fill this gap, in the present study effects of methylphenidate on error-related performance (post-error slowing) and error-related brain activity (N2, Ne/ERN and Pe) of ADHD children that also participated in the first study were explored in a second, placebo-controlled, double blind study.

\section{Materials and methods}

In the first study, children with ADHD and typically developing control children were compared with respect to behavioural measures associated with error processing such as post-error slowing, and ERP responses that reflect how information processing proceeds in both groups of children before an error is made (stimulus-locked frontal $\mathrm{N} 2$ component) and after the occurrence of an error (response-locked Ne/ERN and Pe components). In study 2 the effects of methylphenidate (MPH) on the same behavioural and ERP parameters were investigated in the same ADHD children in a placebo controlled double-blind design.

\subsection{Participants}

A selection of subjects from an earlier study (Jonkman et al., 1999) was used in the present study. Only subjects that had six or more error trials were included in the analysis. In study 1, this amounted to the inclusion of 10 control children, with a mean age of 10.76 years (S.D. $=1.18$ ) and 10 ADHD children, with a mean age of 9.5 years $($ S.D. $=2.11)$. The total IQ scores were 107.5 $($ S.D. $=9.9)$ and 97.9 (S.D. $=13.3$ ) in control and ADHD groups, respectively. All subjects had total IQ scores above 80 . There was no significant difference in mean age or total IQ between the groups. All ADHD children had a DSM-III-R diagnosis of ADHD made by a psychiatrist and had scores above clinical threshold on Child Behaviour Checklist (CBCL) and Conners teacher Rating Scale (TRF) filled in by, respectively, the parents and teachers. All control children scored below clinical threshold on CBCL and TRF. Children that were on medication (mostly methylphenidate) discontinued medication use for 3 days prior to each test day. For a more detailed description of the diagnostic procedure the reader is referred to an earlier study (Jonkman et al., 1999). In the second study the ADHD sample consisted of nine subjects, of which six were also included in study 1 . The
ADHD samples in studies 1 and 2 did not completely overlap due to subjects having too few error trials or too many ERP artifacts in one of both studies. Furthermore, one subject only completed the first study. The mean age in this group was 9.87 years $($ S.D. $=2.4$ ) and mean total IQ was $97.3($ S.D. $=13.6)$. The present research was carried out in accordance with the Declaration of Helsinki. Informed consent was obtained from the parents of all children, and the study was approved by the Medical Ethical Committee of the University Medical Center Utrecht.

\subsection{Flanker task}

In the flanker task subjects had to respond to a centrally presented arrow. The subject's task was to press a hand-held button with the right thumb in response to the arrow stimulus pointing to the right and with the left thumb to a left pointing arrow. In three conditions, the central target arrow was flanked by either two arrows pointing in the same direction as the target arrow (congruent; $>>>>>$ or $<<<<<$ ) pointing in the opposite direction (incongruent; $<<><<$ or $>><>>$ ) or by neutral flankers $(++>++$ or $++<++)$. In the fourth, target alone condition, no flankers were presented. In total 480 stimuli were presented in three blocks of the same length. Each of these blocks consisted of 320 stimuli of which half were warning signals (a dot in the centre of the screen). The other 160 signals were the task relevant stimuli; the probability of stimuli in all four categories was $25 \%$. Within each stimulus category half of the trials required a left-hand response and half a right-hand response. The visual angle of an arrow was $1.02^{\circ}$ by $1.02^{\circ}$ with flankers (incongruent, congruent and neutral conditions) the entire stimulus array had a visual angle of $6.45^{\circ}$ width and a height of $1.02^{\circ}$. The duration of each task block was about $7 \mathrm{~min}$; the stimulus duration of the warning signals and target stimuli was, respectively, 0.2 and $0.5 \mathrm{~s}$. Between warning and task stimuli there was a fixed interstimulus-interval (ISI) of $0.3 \mathrm{~s}$. The ISI between task stimuli varied randomly between 1.7 and $2.4 \mathrm{~s}$. The subjects were instructed to respond as fast and accurate as possible, no RT deadline was imposed.

\subsection{Procedure}

On arrival in the laboratory, the child (accompanied by one of the parents) was familiarized with the procedure. After attachment of the electrode cap and EOG electrodes, the child underwent a practice task of about 2 min, until a criterion of $85 \%$ correct responses was reached. After completion of the experiment subjects were rewarded with a small toy. For the drug study, each ADHD child was measured in two laboratory sessions 1 week apart, after treatment with either a placebo or $15 \mathrm{mg} \mathrm{MPH}$, administered in a counterbalanced and double-blind manner. The received dosages of MPH varied between 0.36 and $0.79 \mathrm{mg} / \mathrm{kg}$ (the group mean was 0.53 , S.D. $=0.16 \mathrm{mg} /$ $\mathrm{kg}$ ). For a more elaborate procedure description see Jonkman et al. (1999).

\subsection{Electroencephalographic (EEG) and electro-oculographic (EOG) recordings}

The EEG activity was recorded from tin electrodes by means of an electrocap. Linked ear lobe electrodes, each connected with a $15-\mathrm{k} \Omega$ resistor, were used as reference. Horizontal EOG was recorded using tin electrodes attached to the outer canthus of both eyes by means of adhesive rings. Similarly, vertical EOG was recorded from infraorbital and supraorbital electrodes placed in line with the pupil of the left eye. A ground electrode was attached to the middle of the forehead. For EEG and EOG, electrode impedance was kept below $10 \mathrm{k} \Omega$. All EEG signals were amplified with a time constant of $10 \mathrm{~s}$. EOG signals were amplified with a time constant of $36 \mathrm{~s}$. All signals were filtered online (band-pass filter from 0.05 to $40 \mathrm{~Hz}, 24 \mathrm{~dB} /$ octave) and digitized at a rate of $256 \mathrm{~Hz}$.

\subsection{Signal analysis}

For the N2, Ne/ERN and Pe analyses only the data from three midline scalp electrodes Fz, Cz and Pz were analyzed. All EEG and EOG data were analyzed using Neuroscan 4.3 software. EEG and EOG epochs were filtered offline with a $30-\mathrm{Hz}, 24 \mathrm{~dB} /$ octave digital low-pass filter. The individual EEG was corrected 
for vertical EOG artifacts by subtracting vertical EOG from EEG epochs according to a linear derivation procedure (Semlitsch et al., 1986). An average eye movement artifact was computed by manually selecting a minimum of 20 representative eye blinks. Last, all EEG epochs containing artifacts (saturation of the A/D converter or amplitude greater than -100 or $100 \mu \mathrm{V}$ ) were removed from the database.

\subsubsection{Stimulus locked ERP analyses}

To investigate processing of response conflict, using the N2 component, the signals were averaged time-locked to the stimulus. First, for all subjects, the continuous signal was divided into stimulus-locked epochs that started $100 \mathrm{~ms}$ before the stimulus and continued $1200 \mathrm{~ms}$ post-stimulus. ERP signals were aligned to the $100 \mathrm{~ms}$ pre-stimulus baseline. First, to confirm that the stimuluslocked N2 was related to conflict processing, ERPs were averaged to all congruent and incongruent trials to which subjects responded correctly. Next, correct and incorrect stimulus-locked ERPs were derived by averaging separately across trials with correct responses and error trials (collapsed over stimulus categories); trials with responses faster than $150 \mathrm{~ms}$ and later than $1500 \mathrm{~ms}$ were excluded from the analyses. In all N2 analyses, N2 peak amplitude and latency were determined in a time window from 290 to $450 \mathrm{~ms}$ post-stimulus.

\subsubsection{Response locked analyses}

To quantify error-related potentials, i.e., the Ne/ERN and the Pe, the signals were averaged time-locked to the response. Since, baseline intervals directly preceding the response are usually confounded by stimulus-related components or at least do not contain the assumed zero activity, Luck (2005) suggests to use either: (1) a baseline interval "that precedes the response enough so that it always precedes the stimulus" or (2) "to use the average voltage of the entire averaging epoch as the baseline" (p. 237). Since the first option is difficult because of large variability in RT within and between groups a baseline covering the entire epoch from -1200 pre-response to $600 \mathrm{~ms}$ post-response was chosen. To compare our results with those of other ADHD-ERN/Pe studies (Wiersema et al., 2005; Burgio-Murphy et al., 2007; Van Meel et al., 2007), we also performed all ERN/Pe analyses with a -100 to 0 pre-response baseline; this did not change Group differences in an important way but it did reduce the methylphenidate effects (the Drug $\times$ Response type interaction was now marginally significant at $\mathrm{Cz}(p<.1)$. Signals from incorrect and correct response trials were separately averaged to obtain incorrect and correct response-locked ERPs; trials with responses faster than $150 \mathrm{~ms}$ and later than $1500 \mathrm{~ms}$ were excluded from the analyses. In the incorrect ERPs, peak amplitude and latency of the Ne/ERN were manually scored in the individual ERPs by two independent experienced ERP researchers, in a time-window from 25 to $180 \mathrm{~ms}$ after the response. The inter-rater-reliability of Ne/ERN latency scores for incorrect trials of the individual raters was high $(r=.99$ at $\mathrm{Fz}$ and .92 at $\mathrm{Cz}$ in both studies). Due to the absence of an Ne/ERN-like negativity from 25 to $180 \mathrm{~ms}$ in the correct response-locked ERPs, correct amplitudes were determined in a time window of $20 \mathrm{~ms}$ around the time point at which the $\mathrm{Ne} / \mathrm{ERN}$ occurred in the individual ERPs for incorrect trials. For Pe scoring, mean area amplitudes were computed in time windows from 200 to 450 and 200 to $300 \mathrm{~ms}$ post-response in study 1 (ADHD vs. controls) and study 2 (placebo vs. MPH), respectively. The choice of these windows was based on inspection of the grand average error-related waveforms and on similar ERP studies (Wiersema et al., 2005).

\subsubsection{Matching of trials between groups for computation of ERP averages}

It was recently pointed out (Thomas et al., 2004) that when fewer than 27 trials are used for averaging of ERPs, the signal-to-noise ratio is low, resulting in systematic overestimation of especially peak amplitudes. Since control children made significantly fewer errors, their incorrect average ERPs contained fewer trials than the ERPs of ADHD children and this might lead to overestimation of peak amplitudes of the different ERP components in the control group. Therefore, the number of error trials in the incorrect averages was matched between the ADHD and control children. The number of artifact-free error trials included in the individual averages of healthy children ranged from 6 to 48 trials $(M=20.4$, S.D. $=12)$. Before matching, the artifact-free error trials of ADHD children in study 1 (baseline) ranged from 6 to $96, M=47.5$, S.D. $=30$ ). To match the number of trials between groups; first, the children in each group were rank-ordered on their number of error trials. Second, the number of error trials that were used for calculating the averages of ADHD children were matched to those of the control children with the same rank order. Thus, if a control subject had 20 incorrect trials and the ADHD child with the same rank order had more than 20 error trials, the error ERP of the ADHD child with the same rank order was averaged over the first 20 incorrect trials. Matched averages were used for all subsequent analyses. To be able to compare our results with those of previous studies that did not match on error trials between groups we also performed all analyses in study 1 without matching; this did however not appear to influence the results in an important way.

\subsection{Statistical analysis}

Performance measures included the percentage of correct responses $(\%$ hits), mean reaction time (RT) to correct and wrong responses (hit-RT and errorRT; only RTs between 150 and $1500 \mathrm{~ms}$ were included) and post-error slowing. For all dependent variables repeated measures analysis of variance was applied. For \% hits and hit-RT the analyses included a within factor Stimulus type (congruent, incongruent, neutral and target alone) and a between factor Group (ADHD, controls). Based on our interest in effects of response incongruency, Significant Group $\times$ Stimulus type (four levels) interactions were followed up by testing for Group effects between incongruent and neutral and incongruent and congruent stimuli, respectively. Because of the few errors in congruent and target-alone conditions, the error-RT analysis included a within factor Stimulus type with only two levels (incongruent vs. neutral). Post-error slowing was defined as the mean difference in RT between correct response trials that were preceded by an error and correct responses trials that were not preceded by an error. Post-error slowing effects were explored by performing a repeated measures ANOVA including a between subjects factor Group (ADHD vs. controls), and within-subjects factor Slowing (RT_error + 1 vs. RT_correct + 1).

To compare the pre-response conflict monitoring and error-related potentials between ADHD and control children, separate repeated measures ANOVAs were carried out for the following dependent variables: amplitude and latency of the stimulus-locked N2, amplitude and latency of the responselocked Ne/ERN, and amplitude of the Pe. All analyses comprised a between subjects factor Group (ADHD vs. controls) and a within-subjects factor Response type (incorrect vs. correct trials). For Ne/ERN latency, only the effect of Group was investigated by an independent $t$-test. The N2 and Ne/ERN analyses were performed at $\mathrm{Fz}$ and $\mathrm{Cz}$ leads. The $\mathrm{FCz}$ electrode, at which the $\mathrm{Ne} / \mathrm{ERN}$ is maximal in adults was not included since it was not part of the current electrode configuration. The Pe analyses were performed at $\mathrm{Cz}$ and $\mathrm{Pz}$.

To answer the research questions regarding effects of MPH the same statistical tests were performed at the same variables and leads but now the between subjects factor Group was in all tests replaced by the within subjects factor Drug (placebo vs. MPH). Since the design was not completely balanced (five subjects first received placebo followed by MPH, while four subjects had the reverse order), the factor Order was covaried in case of significant Drug $\times$ Response type interactions; order had no influence on these interactions. For all tests, unless otherwise mentioned, a two-tailed significance level of $5 \%$ was adopted.

\section{Results}

\subsection{Behavioural analyses}

\subsubsection{Percentage hits and hit reaction time}

Analyses were performed on percentage correct responses (\% hits) and reaction time on correct response trials (hit-RT) in the four stimulus conditions. For percentage of correct responses a planned contrast was performed to test whether in this smaller group of subjects the effect reported in Jonkman et al. (1999) of ADHD subjects making more errors than controls, especially in the incongruent condition, could be replicated. The analysis showed a significant Stimulus type - 
$\times$ Group interaction $(F(3,16)=3.04, p=.03$, one-tailed $)$, thus further tests were performed to compare group differences in hit\% between incongruent and the other conditions. Stimulus type (2) $\times$ Group interactions were found for incongruent versus neutral $(F(1,18)=5,9, p<.05)$ and incongruent versus congruent $(\mathrm{F}(1,18)=4.8, p<.05)$ stimuli. These effects indicate that the decrease in accuracy in the incongruent condition (when compared to neutral or congruent conditions) was significantly larger in ADHD group (61\% incongruent vs. $83 \%$ neutral) than in the control group ( $83 \%$ incongruent versus $94 \%$ neutral). With regard to hit-RT, a significant stimulus type effect $(F(3,16)=13.3, p<.00001)$ was further explored and indicated that reaction times were slowest in the incongruent condition, compared to all other three conditions (see Table 1). A marginally significant Group effect $(F(1,18)=3.04$, $p=.09$ ), indicated that response times were generally slower in ADHD children.

In the placebo-methylphenidate comparison, with regard to $\%$ hits main effects of stimulus type $(F(3,6)=7.6, p<.05)$ and $\operatorname{drug}(F(1,8)=8.2, p<.05)$ were found. Further testing of the stimulus type effect led to the finding that in both the placebo and methylphenidate conditions, the percentage of correct responses was lowest in the incongruent condition, compared to all other three conditions (all post hoc tests $p<.05$ ). The drug effect indicated that methylphenidate significantly increased the number of correct responses of ADHD subjects in all four stimulus conditions (see Table 1). For hit-RT a significant Stimulus type (4) $\times$ Drug interaction occurred $(F(3,6)=7.4$, $p<.05$ ) but further testing of this interaction did not lead to any significant effects; for mean hit-RTs in placebo and methylphenidate conditions see Table 1 .

\subsubsection{Reaction time on error trials}

To check for Group differences in reaction time on error trials (error-RT) (study 1) a planned contrast was performed including only incongruent and neutral conditions. This analysis yielded a significant stimulus type effect $(F(1,17)=6.24, p<.05)$, indicating that mean error RT was slower when making an error in the incongruent than in the neutral condition $(596 \mathrm{~ms}$ vs. $495 \mathrm{~ms}$ ). There were no differences between Groups.

Table 1

Behavioural results in the flanker task

\begin{tabular}{lclll}
\hline & Incongruent & Neutral & Congruent & Target-alone \\
\hline $\begin{array}{l}\text { Hit percentage } \\
\text { Controls }\end{array}$ & $83(9.1)$ & $94(7.8)$ & $95(6.1)$ & $95(9.5)$ \\
ADHD & $61(21.8)$ & $83(14.5)$ & $84(13.4)$ & $83(12.0)$ \\
ADHD-placebo & $76(22.0)$ & $92(5.3)$ & $91(5.7)$ & $88(6.4)$ \\
ADHD-MPH & $81(20.4)$ & $94(3.6)$ & $93(5.8)$ & $94(3.5)$ \\
Hit-RT (ms) & & & & \\
Controls & $612(162)$ & $533(135)$ & $529(141)$ & $509(132)$ \\
ADHD & $737(220)$ & $651(164)$ & $648(165)$ & $614(151)$ \\
ADHD-placebo & $653(170)$ & $583(131)$ & $582(141)$ & $569(147)$ \\
ADHD-MPH & $653(179)$ & $572(132)$ & $579(145)$ & $556(143)$ \\
\hline
\end{tabular}

Means and S.D. (between parentheses) of \% correct responses (hits) and hit reaction time (Hit-RT) in the four stimulus conditions in study 1 (ADHDcontrol comparison) and study 2 (placebo-methylphenidate (MPH) comparison in ADHD children).
The drug study (study 2) did not show any significant effects of stimulus type or drug on error-RT in incongruent versus neutral conditions. Although error-RTs were on average 54 and $82 \mathrm{~ms}$ slower in the incongruent than in the neutral condition in placebo and methylphenidate sessions, respectively, this difference did not reach significance.

\subsubsection{Post-error slowing}

Post-error slowing was analyzed by comparing RT on correct response trials following an error with RT on all second correct response trials (both averaged over all four stimulus conditions). In study 1 , the mean RTs for correct responses preceded by an error and for all second correct response trials were $672 \mathrm{~ms}($ S.D. $=152)$ and $658 \mathrm{~ms}($ S.D. $=166)$, respectively, in the ADHD group and $560 \mathrm{~ms}($ S.D. $=170)$ and $546 \mathrm{~ms}$ (S.D. = 136) in the control group. The analysis did not yield any significant effects of Trial type or Group, leading to the conclusion that in neither group there was significant slowing of responses after making an error. The mean number of errors followed by a correct trial was 19 (S.D. $=11$; range from 6 to 43 ) in the control group and 47 (S.D. $=26$; range from 8 to 87 )

Table 2

Means and S.D. (between parentheses) of N2 and ERN peak amplitude and latency and Pe area amplitude for incorrect and correct responses in study 1 (ADHD-control comparison) and study 2 (placebo and methylphenidate comparison in ADHD children; six of the nine children in study 2 also participated in study 1)

\begin{tabular}{|c|c|c|c|c|}
\hline & \multicolumn{2}{|c|}{ Incorrect responses } & \multicolumn{2}{|c|}{ Correct responses } \\
\hline & $\mathrm{Fz}$ & $\mathrm{Cz}$ & $\mathrm{Fz}$ & $\mathrm{Cz}$ \\
\hline \multicolumn{5}{|l|}{ N2 amplitude $(\mu \mathrm{V})$} \\
\hline ADHD & $-2.6(7.1)$ & $-5.3(4.8)$ & $0.4(5.6)$ & $-3.3(4.1)$ \\
\hline Controls & $-1.2(7.8)$ & $-1.9(5.5)$ & $3.5(6.2)$ & $1.2(4.4)$ \\
\hline Placebo & $-3.8(6.0)$ & $-5.0(5.4)$ & $-0.8(8.3)$ & $-2.8(6.3)$ \\
\hline Methylphenidate & $-5.8(8.6)$ & $-4.2(7.4)$ & $0.2(6.4)$ & $-1.8(6.4)$ \\
\hline \multicolumn{5}{|l|}{ N2 latency (ms) } \\
\hline ADHD & $360(38)$ & $341(23)$ & $377(42)$ & $361(28)$ \\
\hline Controls & $382(45)$ & $375(47)$ & $391(45)$ & $374(47)$ \\
\hline Placebo & $362(55)$ & $357(45)$ & $365(55)$ & 357 (39) \\
\hline Methylphenidate & $393(48)$ & 367 (44) & $356(47)$ & $360(47)$ \\
\hline \multicolumn{5}{|l|}{ ERN amplitude $(\mu \mathrm{V})$} \\
\hline ADHD & $-5.2(7.3)$ & $-6.8(9.4)$ & $-0.1(4.5)$ & $3.4(7.9)$ \\
\hline Controls & $-6.9(4.5)$ & $-6.6(7.6)$ & $-0.2(6.3)$ & $3.7(7.4)$ \\
\hline Placebo & $-6.7(4.5)$ & $-6.0(3.9)$ & $-0.9(2.7)$ & $1.3(3.7)$ \\
\hline Methylphenidate & $-5.7(1.7)$ & $-9.3(6.1)$ & $-0.8(3.5)$ & $1.0(6.6)$ \\
\hline \multicolumn{5}{|l|}{ ERN latency (ms) } \\
\hline ADHD & $100(70)$ & $96(53)$ & - & - \\
\hline Controls & $60(24)$ & $50(25)$ & - & - \\
\hline Placebo & $51(40)$ & $51(34)$ & - & - \\
\hline \multirow[t]{3}{*}{ Methylphenidate } & $82(51)$ & $71(51)$ & - & - \\
\hline & \multicolumn{2}{|c|}{ Incorrect responses } & \multicolumn{2}{|c|}{ Correct responses } \\
\hline & $\mathrm{Cz}$ & $\mathrm{Pz}$ & $\mathrm{Cz}$ & $\mathrm{Pz}$ \\
\hline \multicolumn{5}{|l|}{ Pe amplitude $(\mu \mathrm{V})$} \\
\hline ADHD & $3.4(7.4)$ & $7.4(5.6)$ & $-1.5(4.9)$ & $-3.1(4.5)$ \\
\hline Controls & $11.2(7.5)$ & $11.8(5.6)$ & $-3.6(3.2)$ & $-5.2(2.1)$ \\
\hline Placebo & $1.8(4.8)$ & $4.5(6.6)$ & $-2.8(4.2)$ & $-2.4(3.8)$ \\
\hline Methylphenidate & $6.0(4.8)$ & $9.1(7.9)$ & $-1.9(4.7)$ & $-2.1(3.6)$ \\
\hline
\end{tabular}


in the ADHD group. To compare our results with those of some other studies, we repeated the analysis by including mean RT over all correctly responded trials (instead of correct-correct RTs). This analysis did not yield different results.

In study 2, there also were no significant effects of Trial type or drug. The mean RTs for correct responses preceded by an error and for all second correct responses were, respectively, 583 (S.D. = 141) and 593 (S.D. = 145) $\mathrm{ms}$ in the placebo condition and $581($ S.D. $=147)$ and $586($ S.D. $=145) \mathrm{ms}$ in the MPH condition. Thus, in neither the placebo nor the methylphenidate condition did the ADHD children show post-error slowing.

\subsection{Event-related potential analyses}

The means and standard deviations of peak amplitude and latency measures of $\mathrm{N} 2$ and $\mathrm{Ne} / \mathrm{ERN}$ (at $\mathrm{Fz}$ and $\mathrm{Cz}$ ) and the mean area amplitudes of $\mathrm{Pe}$ (at $\mathrm{Cz}$ and $\mathrm{Pz}$ ) are depicted in Table 2. Stimulus and response-locked averages in the two groups are depicted in Figs. 1 and 2, respectively.

\subsubsection{Stimulus-locked N2}

First, a planned contrast at $\mathrm{Fz}$ was performed to check whether the stimulus-locked N2 was sensitive to the incon-

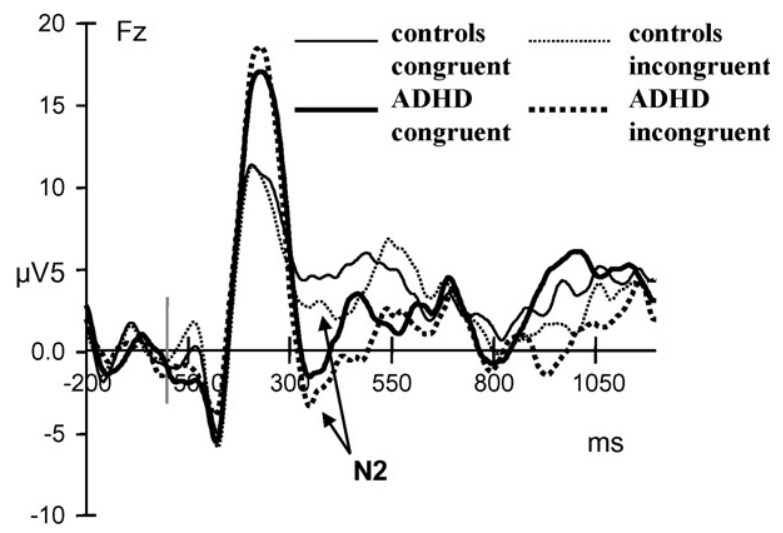

Fig. 1. Stimulus-locked grand average ERPs at electrode Fz in ADHD and control groups in congruent and incongruent conditions (only correctly responded trials) showing an enlarged N2 in the incongruent condition in both groups.

gruence manipulation (larger amplitude to incongruent than congruent stimuli on correctly responded trials), as should be the case when it is related to conflict processing (Van Veen and Carter, 2002a; Yeung et al., 2004). The repeated measures analysis indeed revealed a main Stimulus type effect $(F(1$, $18)=3.40, p<.05$, one-tailed), showing that ADHD and control subjects had more negative $\mathrm{N} 2 \mathrm{~s}$ in response to
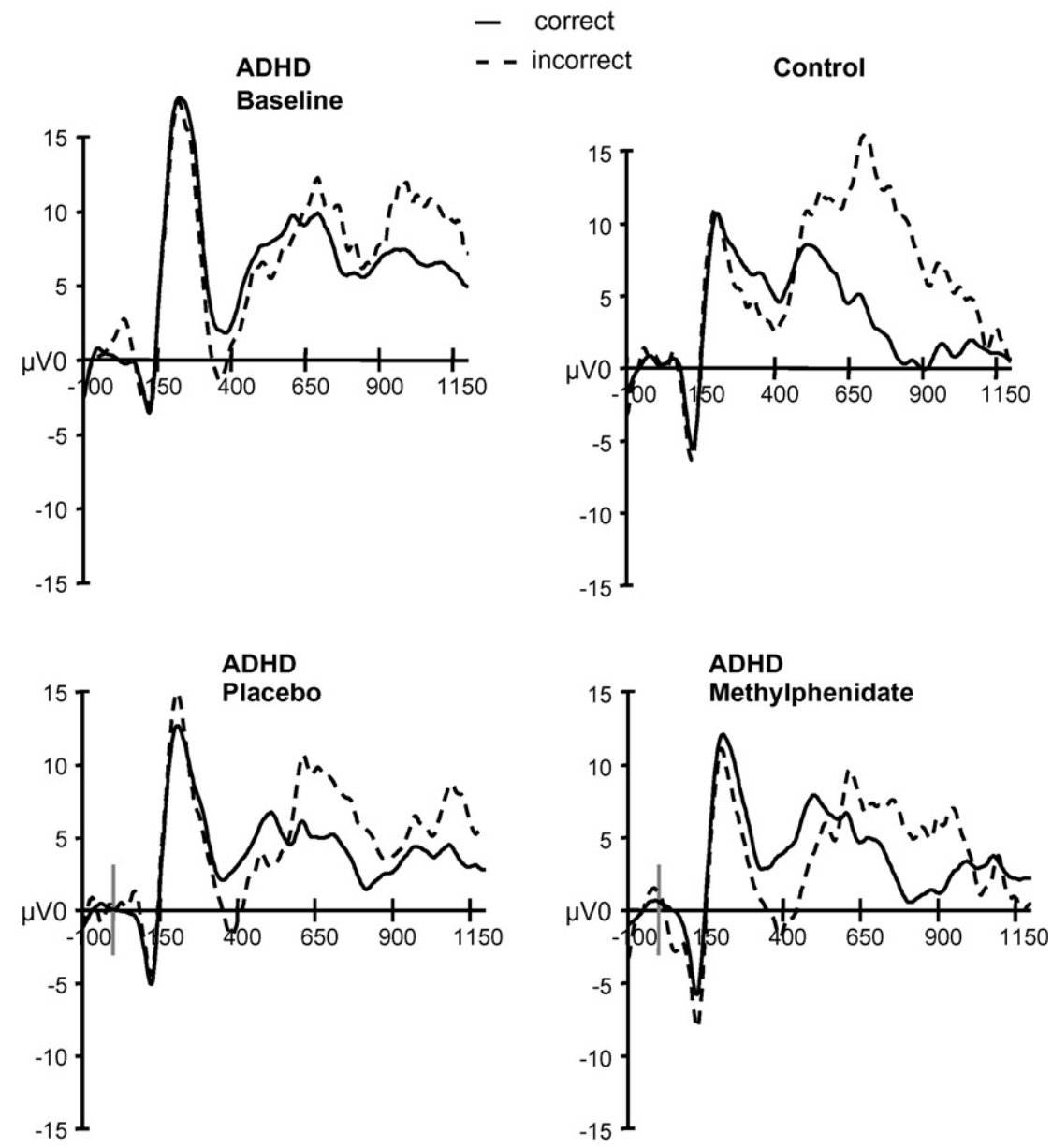

Fig. 2. Stimulus-locked grand average ERPs at electrode Cz in ADHD and control groups (study 1) and in placebo and methylphenidate conditions (study 2) for correct and incorrect response trials. 
incongruent stimuli; this effect did not differ between ADHD and control groups (see Fig. 1).

A subsequent stimulus-locked N2 analysis was performed to investigate whether control and ADHD children differed in pre- error conflict processing (study 1). For this purpose ERPs were computed separately for trials to which the children had responded correctly and for error trials (collapsed over stimulus categories). The mean N2 latency at $\mathrm{Cz}$ was, respectively, 375
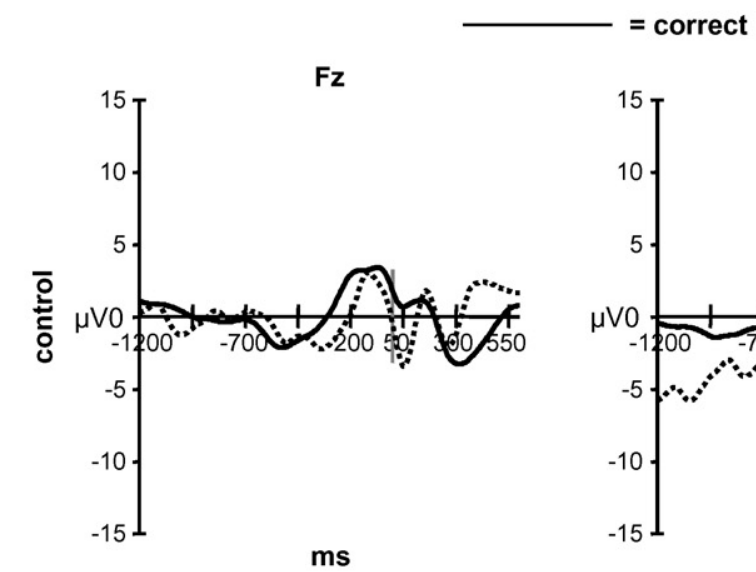

$\mathrm{Cz}$
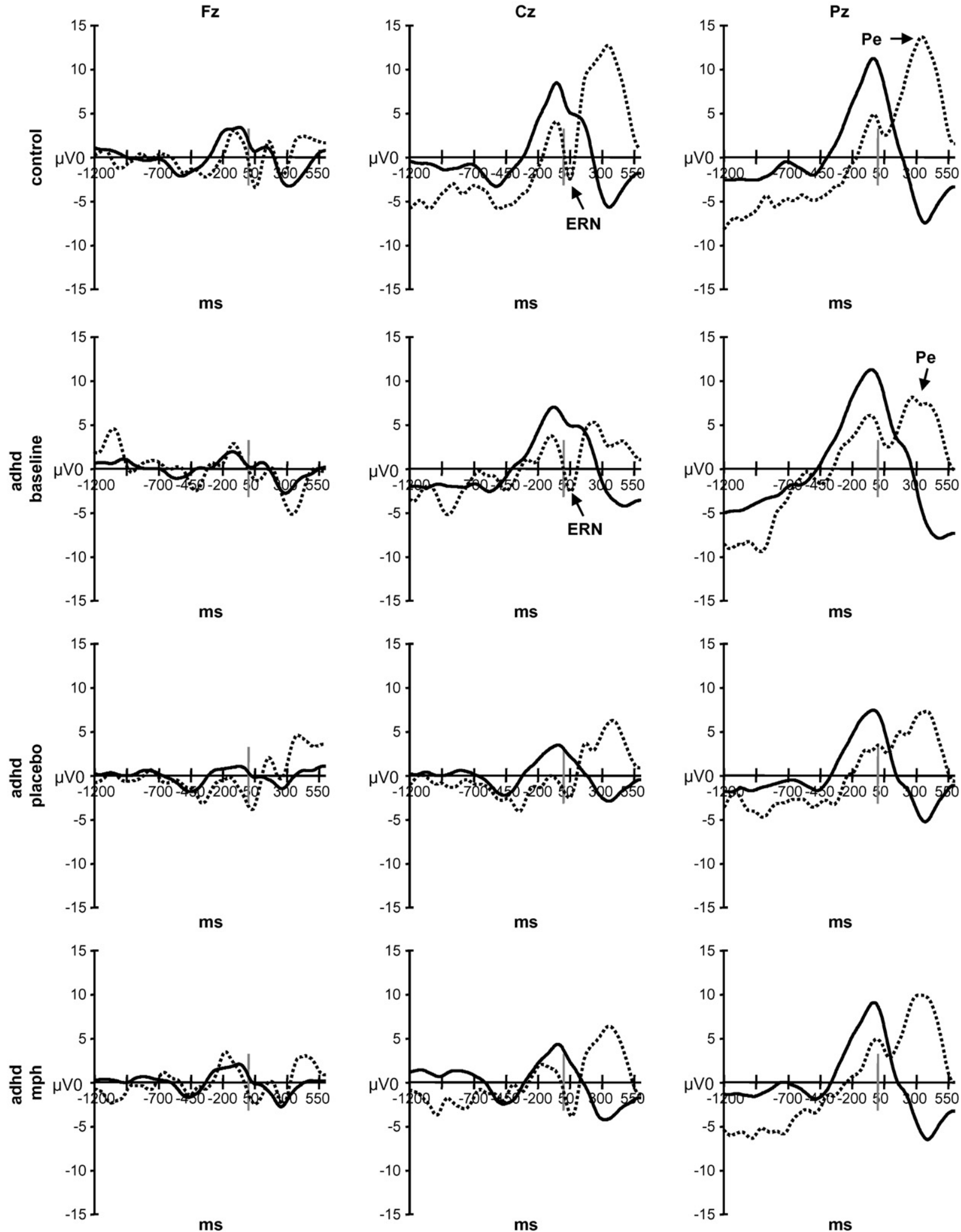

Fig. 3. Response-locked grand average ERPs (Ne/ERN and Pe effects) at Fz, Cz and Pz in ADHD and control groups (study 1) and placebo and methylphenidate conditions for correct and incorrect response trials. 
and $341 \mathrm{~ms}$ in control and ADHD children, thus, the $\mathrm{N} 2$ occurred well before the generation of correct or incorrect responses (between 495 and $753 \mathrm{~ms}$ ) in both groups, suggesting an independence of response processes. A significant main effect of Response type occurred at Fz, $F(1,18)=4.13, p=.057$ and $\mathrm{Cz}, F(1,18)=13.7, p<.005$, and indicated that in both groups, the $\mathrm{N} 2$ amplitude was significantly more negative on incorrect response trials than on correct response trials (see Fig. 2 and Table 2). At Fz, a near-significant main effect of Group, $F(1,18)=3.6, p<.08$, showed that in both response conditions, the $\mathrm{N} 2$ amplitudes were more negative in ADHD children.

In study 2, in which effects of methylphenidate were investigated, again a significant main effect of response type occurred at $\mathrm{Fz}(F(1,8)=15.6, p<.005)$ and $\mathrm{Cz}(F(1,8)=6.2$, $p<.05)$; $\mathrm{N} 2$ amplitude was significantly enhanced in error trials compared to correct response trials (see Fig. 2). No significant drug effects on $\mathrm{N} 2$ amplitude were found. In neither study 1 nor 2 , the $\mathrm{N} 2$ latency analysis showed main or interaction effects of response type, Group or drug.

\subsection{2. $\mathrm{Ne} / \mathrm{ERN}$}

In study 1 , the response-locked Ne/ERN analysis revealed significant main effects of Response type (incorrect vs. correct responses $)$ at $\mathrm{Fz}(F(1,18)=20.8, p<.00001)$ and $\mathrm{Cz}(F(1$, $18)=38.5, p<.00001)$. As can be seen in Fig. $3(\mathrm{Cz})$ and Table 2, both ADHD and control children generated a pronounced negativity within $30-100 \mathrm{~ms}$ after making an error, whereas, such negativity was absent after correct responses. There were no significant Group $\times$ Response type interactions ( $p=.39$ and .98 at $\mathrm{Fz}$ and $\mathrm{Cz}$, respectively).

In study 2, a significant Ne/ERN effect (larger negativity during incorrect than correct response trials) was also seen in ADHD children during placebo and methylphenidate conditions as revealed by main effects of response type at Fz $(F(1$, $8)=13.9, p<.01)$ and $\mathrm{Cz}(F(1,8)=36.6, p<.00001)$ (see Fig. 3; $\mathrm{Cz}$ electrode). Methylphenidate did not influence this $\mathrm{Ne} / \mathrm{ERN}$ effect, as was revealed by the absence of drug effects. No Group or drug effects were found on Ne/ERN latency on error trials. Since in the present study no Ne/ERN-like negativity occurred after correct responses, no latency could be scored in the 'correct' ERP.

\subsection{3. $P e$}

In the ADHD-control comparison (study 1), in both groups, response type effects were marked by a large positivity (the $\mathrm{Pe}$ ) following the Ne/ERN on error trials that was not present on correct response trials (main response type effects at both $\mathrm{Cz}$ and $\mathrm{Pz} ; p<.00001)$. Furthermore, significant Group $\times \mathrm{Re}-$ Response type interactions occurred for response locked amplitudes in a time window from 200 to $450 \mathrm{~ms}$ at $\mathrm{Cz}(F(1$, $18)=8.8, p<.01)$ and $\mathrm{Pz}(F(1,18)=5.37, p<.05)$. Further testing showed that whereas, response type effects were significant in both groups at $\mathrm{Pz}$, the response type effect was smaller in the ADHD $(F(1,9)=6.3, p<.05)$, than the control group $(F(1,9)=20.2, p<.005)$; see Fig. 3 and Table 2 .
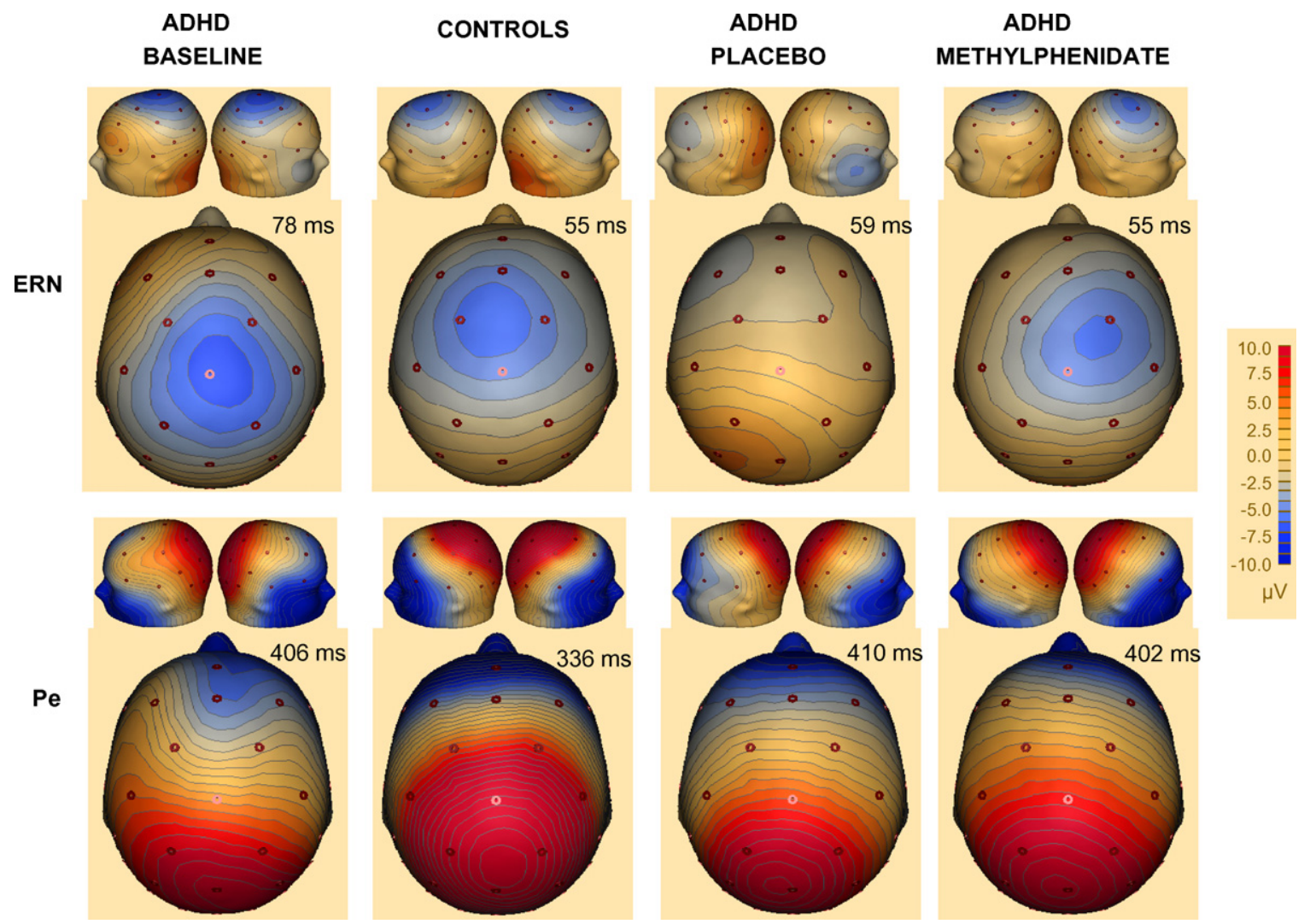

Fig. 4. Voltage maps across 27 electrodes for the response-locked Ne/ERN and Pe in ADHD (ADHD baseline) and control groups (study1) and in ADHD subjects in placebo and methylphenidate conditions (study 2). 
The placebo-methylphenidate analyses (study 2) showed main effects of response type at $\mathrm{Cz}(F(1,8)=16.2, p<.005)$ and $\mathrm{Pz}(F(1,8)=21.0, p<.005)$, indicating the presence of a large positivity (Pe) from 200 to $300 \mathrm{~ms}$ post-response only on error trials (see Table 2 and Fig. 3). Furthermore, at $\mathrm{Cz}$ a significant Drug $\times$ Response type interaction $(F(1,8)=6.3$, $p<.05)$ was found, and at $\mathrm{Pz}$ the interaction was marginally significant $(F(1,8)=4.2, p<.1)$. Further post-hoc testing indicated that at $\mathrm{Cz}$, methylphenidate significantly enhanced $\mathrm{Pe}$ amplitude after incorrect responses (drug: $t(8)=1.9, p<.05$ ) whereas the drug had no such effect on the Pe amplitude after correct responding (drug: $t(8)=-.81, p=.44$ ) (see Fig. 3).

\subsection{Topographical maps}

Topographical maps of Ne/ERN and Pe amplitude across 27 electrodes (average referenced data) are displayed in Fig. 4. Except in the placebo condition, the maps of the Ne/ERN are dominated by a negative field in the centro-medial scalp region, replicating adult studies (Dehaene et al., 1994; Miltner et al., 1997; Van Veen and Carter, 2002a; Luu et al., 2003). The Pe maps display a large positive field over medial parietal cortex $(\mathrm{Pz})$ in both groups and placebo and methylphenidate conditions (also replicating adult studies; Davies et al., 2001; O’Connell et al., 2007).

\section{Discussion}

Children with ADHD usually make more errors than typically developing children in response-conflict tasks. The aim of the present study was to elucidate responsible neurobiological and cognitive processes. To this purpose in a first study we measured ERPs associated with conflict and error processing in a flanker task in ADHD and control children and in a second study we investigated the effects of MPH on such processing in children with ADHD.

\subsection{Conflict and error processing in children with ADHD and healthy controls}

\subsubsection{Behavioural data}

The behavioural results show that both groups of children made more errors and generally responded slower in the incongruent condition compared to the neutral condition, indicating the presence of response conflict. The delayed error reaction times in the incongruent condition further suggest that in both groups errors were not made impulsively but instead seem to occur after conflict processing has taken place. As was reported earlier, ADHD children made more errors than control children in the incongruent compared to the neutral condition, indicating enhanced sensitivity to conflicting response-information (Jonkman et al., 1999; Crone et al., 2003; Scheres et al., 2004). Since there were no between-group differences in correct versus error response times, the increased number of errors in ADHD children does not seem to be the result of impulsive behaviour. To investigate reflection to erroneous behaviour, post-error reaction times were compared with reaction times after correct responses that were not preceded by an error. In speeded choice reaction time tasks, adults often reveal slow responses on post-error trials, which is thought to reflect awareness of the error (Rabbitt, 1966). In the present study, both ADHD and control children revealed post-error slowing of about $20 \mathrm{~ms}$ which, however did not reach significance. Whereas, the absence of post-error slowing has previously been reported in children with attention disorders (ADD) (Sergeant and van der Meere, 1988; Schachar et al., 2004), these studies did report post-error slowing in control children. The absence of post-error slowing in control children in the present study might be due to differences in the type of errors (inhibition failures vs. response-choice errors) or to differences in 'task-awareness'. In stop-signal tasks, due to the occurrence of the stop signal, healthy subjects may become more conscious of their inhibition failures; causing larger posterror slowing.

\subsubsection{ERP data}

The ERP data showed a clear stimulus-locked N2 in correct and incorrect response trials. In both ADHD and control children the N2 was larger on trials in which an error was made. Whereas, it was not possible to include a Congruence factor in this correct/incorrect $\mathrm{N} 2$ analysis due to too few errors in the congruent condition, the $\mathrm{N} 2$ was in both groups significantly enhanced in response to incongruent stimuli to which one responded correctly. This confirms that also in the present study, the N2 amplitude is related to the process of (response) conflict detection (see Van Veen and Carter, 2002a; Yeung et al., 2004 for adult studies). This, together with delayed RT, suggests that both groups experienced more flanker-induced conflict on error trials. Furthermore, there was a trend for ADHD children to show larger overall N2 amplitudes than controls at the $\mathrm{Cz}$ electrode on correct as well as incorrect trials. Such generally enhanced N2 amplitudes in the ADHD group presumably reflect enhanced sensitivity to flanker-induced conflict in these children. Interestingly, Yeung et al. (2004) suggested that errors are mainly generated when responseconflict exceeds a certain threshold level. Applying this line of reasoning to the present data, higher N2 amplitudes in ADHD children could indicate that they reach this threshold more often ultimately causing them to make more errors, particularly in the incongruent condition.

To explore brain responses after making an error, responselocked Ne/ERN and Pe components were computed. In both ADHD and control children enhanced Ne/ERN and Pe responses were found on error-compared to correct response trials. The only group difference in error-related ERPs was a reduced amplitude of the Pe in children with ADHD. The similar Ne/ERN response in both groups of children suggests normal early error detection in ADHD children. Although the absence of Ne/ERN differences complies with results reported by Wiersema et al. (2005), two other studies (Liotti et al., 2005; Van Meel et al., 2007) reported reduced and Burgio-Murphy et al. (2007) reported enhanced Ne/ERN amplitude in children with ADHD. Such inconsistencies might be due to differences in task nature and difficulty. In Wiersema et al. and the present 
study more difficult choice-response paradigms were used and clear differences in performance between ADHD and control groups were present. However, Van Meel et al. (2007) also reported worse performance of ADHD children on a choiceresponse flanker task but did find a reduced ERN in children with ADHD. A more methodological explanation might lie in the number of trials used for computation of correct and incorrect error ERPs. In Liotti et al. (2005) incorrect averages of ADHD children were computed over five times more trials than those of control children, which might have caused the difference in ERN amplitude (Thomas et al., 2004). In Van Meel et al. (2007) it is not clear how large differences in error trials included in the ERP averages in ADHD and control groups were but ADHD children made significantly more errors. In the study by Burgio-Murphy et al. (2007) and the present study the number of incorrect trials was matched between groups and ERN amplitudes in the ADHD group were, respectively, found to be larger or similar to that of controls.

An important remaining question concerns the functional significance of the reduced $\mathrm{Pe}$ amplitude in children with ADHD. Wiersema et al. (2005) reported similar results and suggested that the reduced Pe might signal reduced 'errorawareness'. Such an explanation is supported by recent findings from O'Connell et al. (2007) that in healthy adults the ERN was unaffected by the conscious experience of errors, whereas, the Pe was only seen when participants were aware of committing an error. Such reduced error-awareness might prevent ADHD children to learn from their mistakes and adapt their behaviour accordingly. Such an interpretation might seem congruent with the absence of post-error slowing in ADHD children in the present study, were it not that control children also did not slow their responses after making an error. Furthermore, reviewing the Pe literature; Overbeek et al. (2005) found limited evidence for a link between the Pe and post-error behavioural adaptation. Instead, these authors suggest that the Pe might be a P3b and might hence be related to the processing of the motivational significance of an error. This is an interesting suggestion in light of the general finding that compared to healthy children, ADHD children display reduced $\mathrm{P} 3 \mathrm{~b}$ amplitudes in attention tasks, even when they generate a correct response to salient target stimuli (for reviews see Barry et al., 2003; Jonkman, 2005). Such lower P3b amplitudes are thought to signify reduced processing of target-relevance and might be seen as the cause of enhanced inaccuracy in ADHD children. In this sense, the reduced $\mathrm{Pe}$ in the ADHD group might not be error-specific but perhaps reflects a general deficit to allocate enough attention to relevant events or stimuli. Supporting such an hypothesis, Davies et al. (2001) reported that in healthy adults, the P3 amplitude on correct trials highly correlated with Pe amplitude and concluded that the Pe might be a P3 response generated when the subject realizes that an error is being initiated.

\subsection{Effects of methylphenidate on conflict monitoring and error processing in ADHD children}

In the present study MPH reduced the number of errors in all stimulus conditions but had no specific effect on error reaction time or post-error slowing in ADHD children. In an earlier study by Krusch et al. (1996), MPH was found to increase posterror slowing in ADD which was attributed to enhanced uncertainty and the intention to perform more carefully. Such differences might be due to differences in task paradigms; Krusch et al. included a Sternberg memory search task, requiring much more effort.

There were no effects of MPH on the N2 and Ne/ERNs of children with ADHD. The absence of MPH effects on the ERN deviates from previous data in healthy adults showing enhanced Ne/ERN amplitudes after D-amphetamine (de Bruijn et al., 2004) and reduced Ne/ERN amplitudes after DAantagonists such as haloperidol (Zirnheld et al., 2004; de Bruijn et al., 2006). Although purely speculative, such differences might be caused by differences in the generators of the Ne/ERN between children and adults. In adults, the ERN has been repeatedly localized in anterior cingulate cortex (ACC), whereas a recent study by Rubia et al. (2005) found enhanced activation in posterior cingulate during error processing in healthy adolescents. Such different parts of the cortex have different dopamine (DA) or norepinephrine (NE) connections and methylphenidate is a DA as well as NE agonist. Note, however that due to low temporal resolution, it is not possible to link fMRI activation patterns to specific processes such as ERN and Pe that follow each other closely in time.

MPH significantly enhanced the Pe on incorrect (relative to correct) trials in ADHD children. In light of the earlier interpretation of $\mathrm{Pe}$ as a sign of enhanced conscious processing of relevant events, the Pe enhancement after MPH might mean that the drug causes more efficient allocation of attention to important events (such as an error), thereby increasing errorconsciousness. Such enhanced error-consciousness might be the process through which MPH exerts its positive effects on the performance (reducing errors) of ADHD children in the present study.

Since, MPH is found to increase DA levels in the striatum and DA as well as NE levels in the frontal cortex (Volkow et al., 2001; Madras et al., 2005), both routes might be involved in mediating the positive effects of MPH on Pe and behaviour. MPH is known to increase the action of DA by preventing reuptake through blockade of the DA transporter (DAT). Besides in striatum, high DAT densities have recently also been demonstrated in posterior parietal cortex (PPC) areas like precuneus and posterior cingulum (Telang et al., 1999) and the hippocampus (Lewis et al., 2001). Such areas are known to be involved in the generation of P3b-like activity and the allocation of attention, and O'Connell et al. (2007) recently localized the source of the Pe in the anterior ACC and posterior cingulate-precuneus regions in healthy adults. Furthermore, Rubia et al. (2005) reported reduced activation in posterior cingulate cortex/precuneus in adolescents with ADHD (compared to controls) when making errors in a stop signal task. Whereas, in the present study the topographic maps of the Pe show a medial posterior distribution, due to the relatively low amount of electrodes it was not possible to localize the sources underlying the Pe. Nevertheless, MPH 
might have exerted its positive effects on the Pe in ADHD children through DA alterations in such medial (parietal) posterior areas.

Positive MPH effects on the Pe might also be mediated by NE pathways projecting from the locus coeruleus (LC) to the cortex. Animal studies reveal that the LC plays an important role in the control of vigilance and attention processes (Aston-Jones and Bloom, 1981; Aston-Jones et al., 1991, 2000; Foote et al., 1980) and show that behavioural and brain (P3b) changes during attention tasks are mediated by LC-NE innervations. These findings suggest that MPH might establish its positive effects on behaviour and ERPs in attention tasks by acting on the LC (for a review see Nieuwenhuis et al., 2005). With respect to error processing, Usher et al. (1999) showed that in monkeys, increased error rates in an attention task were associated with relatively highbaseline firing activity in LC. Furthermore, besides changes in tonic LC activity, phasic LC responses have been reported to occur in response to stimuli that have motivational significance or are otherwise salient, such as infrequently presented targets in an oddball task (Pineda et al., 1989; Nieuwenhuis et al., 2005). Such phasic LC responses are thought to cause a release of NE in cortical areas to which LC afferents project when reaching a certain threshold level. Accordingly, it was recently shown (Devoto et al., 2005) that in the rat brain phasic LC stimulation at $12 \mathrm{~Hz}$ resulted in increased noradrenaline levels in caudate nucleus and medial prefrontal but also parietal cortices (where possible generators of the $\mathrm{P} 3 \mathrm{~b}$ and $\mathrm{Pe}$ are reported), while having no effects on dopamine. MPH's effects on the performance and Pe of children with ADHD in the present study might thus have been modulated by effects on LC firing. It was recently suggested that stimulants like MPH may decrease long-term baseline NE activity in LC while increasing phasic NE release during the period of clinical effectiveness (Pliszka, 2005). But such hypotheses clearly need further investigation. Interestingly, O'Connell et al. (2007) recently demonstrated that in healthy adults, the amplitude of the Pe was correlated with tonic EEG measures of cortical arousal and suggested that the Pe "represents a P3-like facilitation of information processing modulated by subcortical arousal systems" (p. 2571).

\section{Summary and conclusions}

In the present study children with ADHD made more errors than healthy controls in a flanker task, especially in the condition in which the target stimulus was flanked by responseincongruent stimuli. Whereas, ADHD children did not show post-error slowing, ERP results showed that on error trials (compared to correct trials) they had larger stimulus-locked $\mathrm{N} 2 \mathrm{~s}$, comparable $\mathrm{Ne} / \mathrm{ERNs}$ and reduced Pe amplitude than typically developing children. These results were interpreted as showing that children with ADHD experienced larger response conflict (larger N2) before making an error, had intact early error-detection mechanisms but deficient late error processing (smaller Pe amplitude), which might indicate less error consciousness. In a second study, methylphenidate was found to reduce the number of errors in low as well as high-conflict conditions and normalized $\mathrm{Pe}$ amplitude in children with ADHD, while having no influence on the stimulus-locked $\mathrm{N} 2$ or $\mathrm{Ne} / \mathrm{ERN}$. In light of current theories and findings, the Pe enhancement after MPH might be seen as a sign of enhanced attention allocation to error events, making ADHD children more conscious of their errors and thereby improving performance.

\section{References}

Arnsten, A.F.T., Li, B.M., 2005. Neurobiology of executive functions: catecholamine influences on prefrontal cortical functions. Biological Psychiatry 57, 1377-1384.

Aston-Jones, G., Bloom, F.E., 1981. Norepinephrine-containing locus coeruleus neurons in behaving rats exhibit pronounced responses to non-noxious environmental stimuli. Journal of Neuroscience 1, 887-900.

Aston-Jones, G., Chiang, C., Alexinsky, T., 1991. Discharge of noradrenergic locus coeruleus neurons in behaving rats and monkeys suggests a role in vigilance. Progress in Brain Research 88, 501-520.

Aston-Jones, G., Rajkowski, J., Cohen, J.D., 2000. Locus coeruleus and regulation of behavioral flexibility and attention. Progress in Brain Research 126, 165-182.

Barry, R.J., Johnstone, S.J., Clarke, A.R., 2003. A review of electrophysiology in attention-deficit/hyperactivity disorder. II. Event-related potentials. Clinical Neurophysiology 114, 184-198.

Bartholow, B.D., Pearson, M.A., Dickter, C.L., Sher, K.J., Fabiani, M., Gratton, G., 2005. Strategic control and medial frontal negativity: beyond errors and response conflict. Psychophysiology 42, 33-42.

Botvinick, M.M., Braver, T.S., Barch, D.M., Carter, C.S., Cohen, J.D., 2001. Conflict monitoring and cognitive control. Psychological Review 108, 624 652 .

Brown, R.T., Amler, R.W., Freeman, W.S., Perrin, J.M., Stein, M.T., Feldman, H.M., Pierce, K., Wolraich, M.L., 2005. Treatment of attention-deficit/ hyperactivity disorder: overview of the evidence. Pediatrics 115, 749-757.

Burgio-Murphy, A., Klorman, R., Shaywitz, S.E., Fletcher, J.M., Marchione, K.E., Holahan, J., Stuebing, K.K., Thatcher, J.E., Shaywitz, B.A., 2007. Error-related potentials in children with attention-deficit hyperactivity disorder, oppositional defiant disorder, reading disorder, and math disorder. Biological Psychology 75, 75-86.

Carter, C.S., Braver, T.S., Barch, D.M., Botvinick, M.M., Noll, D., Cohen, J.D., 1998. Anterior cingulate cortex, error detection, and the online monitoring of performance. Science 280, 747-749.

Crone, E.A., Jennings, J.R., van der Molen, M.W., 2003. Sensitivity to interference and response contingencies in attention-deficit/hyperactivity disorder. Journal of Child Psychology and Psychiatry 44, 214-226.

Davies, P.L., Segalowitz, S.J., Dywan, J., Pailing, P.E., 2001. Error-negativity and positivity as they relate to other ERP indices of attentional control and stimulus processing. Biological Psychology 56, 191-206.

Davies, P.L., Segalowitz, S.J., Gavin, W.J., 2004. Development of response monitoring ERPs in 7-to-25-year-olds. Developmental Neuropsychology 25, 355-376.

de Bruijn, E.R., Hulstijn, W., Verkes, R.J., Ruigt, G.S., Sabbe, B.G., 2004. Drug-induced stimulation and suppression of action monitoring in healthy volunteers. Psychopharmacology 177, 151-160.

De Bruijn, E.R., Sabbe, B.G., Hulstijn, W., Ruigt, G.S., Verkes, R.J., 2006. Effects of antipsychotic and antidepressant drugs on action monitoring in healthy volunteers. Brain Research 1105, 112-129.

Dehaene, S., Posner, M., Tucker, D., 1994. Localization of a neural system for error detection and compensation. Psychological Science 5, 303-305.

Devoto, P., Flore, G., Saba, P., Fa, M., Gessa, G.L., 2005. Stimulation of the locus coeruleus elicits noradrenaline and dopamine release in the medial prefrontal and parietal cortex. Journal of Neurochemistry 92, 368374. 
Eriksen, B.A., Eriksen, C.W., 1974. Effects of noise letters upon the identification of a target letter in a nonsearch task. Perception and Psychophysics 16, 143-149.

Falkenstein, M., Hohnsbein, J., Hoormann, J., Blanke, L., 1991. Effects of crossmodal divided attention on late ERP components. II. Error processing in choice reaction tasks. Electroencephalography and Clinical Neurophysiology 78, 447-455.

Falkenstein, M., Hoormann, J., Christ, S., Hohnsbein, J., 2000. ERP components on reaction errors and their functional significance: a tutorial. Biological Psychology 51, 87-107.

Foote, S.L., Aston-Jones, G., Bloom, F.E., 1980. Impulse activity of locus coeruleus in awake rats and monkeys is a function of sensory stimulation and arousal. Proceedings of the National Academy of Science of the United States of America 77, 3033-3037.

Gehring, W.J., Fencsik, D.E., 2001. Functions of the medial frontal cortex in the processing of conflict and errors. Journal of Neuroscience 21, 9430-9437.

Gehring, W.J., Goss, B., Coles, M.G., Meyer, D.E., David, E., 1993. A neural system for error detection and compensation. Psycholological Science 4, 385-390.

Hajcak, G., McDonald, N., Simons, R.F., 2003. To err is autonomic: errorrelated brain potentials, ANS activity, and post-error compensatory behavior. Psychophysiology 40, 895-903.

Holroyd, C.B., Coles, M.G., 2002. The neural basis of human error processing: reinforcement learning, dopamine, and the error-related negativity. Psychological Review 109, 679-709.

Johnson, K.A., Kelly, S.P., Bellgrove, M.A., Barry, E., Cox, M., Gill, M., Robertson, I.H., 2007. Response variability in attention deficit hyperactivity disorder: evidence for neuropsychological heterogeneity. Neuropsychologia 45, 630-638.

Jonkman, L.M., 2005. Selective attention deficits in children with ADHD: a review of behavioral and electrophysiological studies. In: Gozal, D., Molfese, D.L. (Eds.), Attention Deficit Hyperactivity Disorder: From Genes to Patients. Humana Press, Totowa, NJ, pp. 255-275.

Jonkman, L.M., Kemner, C., Verbaten, M.N., Van Engeland, H., Kenemans, J.L., Camfferman, G., Buitelaar, J.K., Koelega, H.S., 1999. Perceptual and response interference in children with attention-deficit hyperactivity disorder, and the effects of methylphenidate. Psychophysiology 36, 419-429.

Krusch, D.A., Klorman, R., Brumaghim, J.T., Fitzpatrick, P.A., Borgstedt, A.D., Strauss, J., 1996. Methylphenidate slows reactions of children with attention deficit disorder during and after an error. Journal of Abnormal Child Psycholology 24, 633-650.

Lansbergen, M.M., Kenemans, J.L., van Engeland, H., 2007. Stroop interference and attention-deficit/hyperactivity disorder: a review and meta-analysis. Neuropsychology 21, 251-262.

Leuthold, H., Sommer, W., 1999. ERP correlates of error processing in spatial S-R compatibility tasks. Clinical Neurophysiology 110, 342-357.

Lewis, D.A., Melchitzky, D.S., Sesack, S.R., Whitehead, R.E., Auh, S., Sampson, A., 2001. Dopamine transporter immunoreactivity in monkey cerebral cortex: regional, laminar, and ultrastructural localization. Journal of Comparative Neurology 432, 119-136.

Liotti, M., Pliszka, S.R., Perez, R., Kothmann, D., Woldorff, M.G., 2005. Abnormal brain activity related to performance monitoring and error detection in children with ADHD. Cortex 41, 377-388.

Luck, S.J., 2005. An introduction to the event-related potential technique. MIT Press, Cambridge, MA.

Luu, P., Tucker, D.M., Derryberry, D., Reed, M., Poulsen, C., 2003. Electrophysiological responses to errors and feedback in the process of action regulation. Psychological Science 14, 47-53.

Madras, B.K., Miller, G.M., Fischman, A.J., 2005. The dopamine transporter and attention-deficit/hyperactivity disorder. Biological Psychiatry 57, 1397-1409.

Miltner, W., Braun, C., Coles, M.G.H., 1997. Event-related brain potentials following incorrect feedback in a time estimation task: evidence for a "generic" neural system for error detection. Journal of Cognitive Neuroscience 9, 784-798.

Nieuwenhuis, S., Ridderinkhof, K.R., Blom, J., Band, G.P., Kok, A., 2001. Error-related brain potentials are differentially related to awareness of response errors: evidence from an antisaccade task. Psychophysiology $38,752-760$.

Nieuwenhuis, S., Ridderinkhof, K.R., Talsma, D., Coles, M.G., Holroyd, C.B., Kok, A., van der Molen, M.W., 2002. A computational account of altered error processing in older age: dopamine and the error-related negativity. Cognitive, Affective and Behavioral Neuroscience 2, 19-36.

Nieuwenhuis, S., Yeung, N., van den Wildenberg, W., Ridderinkhof, K.R., 2003. Electrophysiological correlates of anterior cingulate function in a go/ no-go task: effects of response conflict and trial type frequency. Cognitive, Affective and Behavioral Neuroscience 3, 17-26.

Nieuwenhuis, S., Aston-Jones, G., Cohen, J.D., 2005. Decision making, the P3, and the locus coeruleus-norepinephrine system. Psychological Bulletin 131, 510-532.

O’Connell, R.G., Dockree, P.M., Bellgrove, M.A., Kelly, S.P., Hester, R., Garavan, H., Rovertson, I.H., Foxe, J.J., 2007. The role of cingulate cortex in the detection of errors with and without awareness: a high density electrical mapping study. The European Journal of Neuroscience 25, 2571-2579.

Overbeek, T.J.M., Nieuwenhuis, S., Ridderinkhof, K.R., 2005. Dissociable components of error processing. On the functional significance of the Pe vis-à-vis the ERN/Ne. Journal of Psychophysiology 19, 319329.

Pineda, J.A., Foote, S.L., Neville, H.J., 1989. Effects of locus coeruleus lesions on auditory, long-latency, event-related potentials in monkey. Journal of Neuroscience 9, 81-83.

Pliszka, S.R., 2005. The neuropsychopharmacology of attention-deficit/hyperactivity disorder. Biological Psychiatry 57, 1385-1390.

Rabbitt, P.M., 1966. Errors and error correction in choice-response tasks. Journal of Experimental Psychology 71, 264-272.

Riba, J., Rodriguez-Fornells, A., Morte, A., Munte, T.F., Barbanoj, M.J., 2005. Noradrenergic stimulation enhances human action monitoring. Journal of Neuroscience 25, 4370-4374.

Rubia, K., Smith, A.B., Brammer, M.J., Toone, B., Taylor, E., 2005. Abnormal brain activation during inhibition and error detection in medicationnaive adolescents with ADHD. American Journal of Psychiatry 162, 1067-1075.

Schachar, R.J., Chen, S., Logan, G.D., Ornstein, T.J., Crosbie, J., Ickowicz, A., Pakulak, A., 2004. Evidence for an error monitoring deficit in attention deficit hyperactivity disorder. Journal of Abnormal Child Psychology 32, 285-293.

Scheffer, M.K., Coles, M.G.H., 2000. Performance monitoring in a confusing world: error-related brain activity, judgments of response accuracy, and types of errors. Journal of Experimental Psychology: Human Perception and Performance 26, 141-151.

Scheres, A., Oosterlaan, J., Geurts, H., Morein-Zamir, S., Meiran, N., Schut, H., Vlasveld, L., Sergeant, J.A., 2004. Executive functioning in boys with ADHD: primarily an inhibition deficit? Archives of Clinical Neuropsychology 19, 569-594.

Segalowitz, S.J., Davies, P.L., 2004. Charting the maturation of the frontal lobe: an electrophysiological strategy. Brain and Cognition 55, 116-133.

Seidel, W.T., Joschoko, M., 1990. Evidence of difficulties in sustained attention in children with ADDH. Journal of Abnormal Child Psychology 18, 217229.

Semlitsch, H.V., Anderer, P., Schuster, P., Presslich, O., 1986. A solution for reliable and valid reduction of ocular artifacts, applied to the P300 ERP. Psychophysiology 23, 695-703.

Sergeant, J.A., van der Meere, J., 1988. What happens after a hyperactive child commits an error? Psychiatry Research 24, 157-164.

Telang, F.W., Volkow, N.D., Levy, A., Logan, J., Fowler, J.S., Felder, C., Wong, C., Wang, G.J., 1999. Distribution of tracer levels of cocaine in the human brain as assessed with averaged [11C]cocaine images. Synapse 31, 290296.

Thomas, D.G., Grice, J.W., Najm-Briscoe, R.G., Miller, J.W., 2004. The influence of unequal numbers of trials on comparisons of average eventrelated potentials. Developmental Neuropsychology 26, 753-774.

Usher, M., Cohen, J.D., Servan-Schreiber, D., Rajkowski, J., Aston-Jones, G., 1999. The role of locus coeruleus in the regulation of cognitive performance. Science 283, 549-554. 
Van Meel, C.S., Heslenfeld, D.J., Oosterlaan, J., Sergeant, J.A., 2007. Adaptive control deficits in attention-deficit/hyperactivity disorder (ADHD): the role of error processing. Psychiatry Research 151, 211-220.

Van Veen, V., Carter, C.S., 2002a. The anterior cingulate as a conflict monitor: fMRI and ERP studies. Physiology and Behavior 77, 477-482.

Van Veen, V., Carter, C.S., 2002b. The timing of action-monitoring processes in the anterior cingulate cortex. Journal of Cognitive Neuroscience 14, 593602.

Volkow, N.D., Wang, G., Fowler, J.S., Logan, J., Gerasimov, M., Maynard, L., Ding, Y., Gatley, S.-J., Gifford, A., Franceschi, D., 2001. Therapeutic doses of oral methylphenidate significantly increase extracellular dopamine in the human brain. Journal of Neuroscience 15, RC121.
Volkow, N.D., Swanson, J.M., 2003. Variables that affect the use and abuse of methylphenidate in the treatment of ADHD. American Journal of Psychiatry $160,1909-1918$.

Wiersema, J.R., van der Meere, J.J., Roeyers, H., 2005. ERP correlates of impaired error monitoring in children with ADHD. Journal of Neural Transmission 112, 1417-1430.

Yeung, N., Cohen, J.D., Botvinick, M.M., 2004. The neural basis of error detection: conflict monitoring and the error-related negativity. Psychological Review 111, 931-959.

Zirnheld, P.J., Carroll, C.A., Kieffaber, P.D., O'Donnell, B.F., Shekhar, A., Hetrick, W.P., 2004. Haloperidol impairs learning and error-related negativity in humans. Journal of Cognitive Neuroscience 16, 1098-1112. 